\title{
PENERAPAN STRUCTURAL EQUATION MODELLING (SEM) UNTUK MENGANALISIS FAKTOR - FAKTOR YANG MEMPENGARUHI KINERJA BISNIS (STUDI KASUS KAFE DI KECAMATAN TEMBALANG DAN KECAMATAN BANYUMANIK PADA JANUARI 2019)
}

\author{
Ade Imma Pramudita ${ }^{1}$, Tatik Widiharih ${ }^{2}$, Rukun Santoso ${ }^{3}$ \\ 1,2,3 Departemen Statistika, Fakultas Sains dan Matematika, Universitas Diponegoro \\ e-mail :widiharih@gmail.com
}

\begin{abstract}
This research is done to examine the effect of quality of service and product attractiveness toward business strategies based on service in order to improving business performance. The sample of this study were Cafe owners in Tembalang Subdistrict and Banyumanik Subdistrict, total are 116 respondents. In this Final Project, the processing of Structural Equation Modeling (SEM) is AMOS software. The results of the analy sis show that servicequality has a positive effect on business strategies based on service to improving business performance. Themost significant factor that affecting business performance is quality of service. Quality of service is important in the performance of a café business. Cafe owners must always pay attention to the quality of café service to customers, because the quality of service is the main consideration for customers to visit cafes.
\end{abstract}

Keywords : quality of service, product attractiveness, business strategies based on service, and business performance.

\section{PENDAHULUAN}

Kompetisi dalam dunia perdagangan semakin terasa. Perubahan lingkungan yang demikian pesat semakin mendukung kompetisi yang sedang terjadi saat ini. Salah satu tujuan utama aktivitas pemasaran seringkali dilihat dari pencapaian kinerja bisnis melalui strategi bisnis berbasis layanan. Strategi bisnis berbasis layanan merupakan bagian terpenting pada kinerja bisnis. Organisasi jasa memfokuskan pada pelatihan karyawan agar terampil, berpengetahuan dan menarik, namun pendekatan tersebut tidak lagi cukup, hal tersebut dikarenakan pelanggan tidak hanya mengutamakan kualitas namun juga mengutamakan kecepatan dalam pelayanan (Khan dan Strong, 2016).

Strategi bersaing berorientasi pelanggan penting pada dunia bisnis dan pemasaran industri. Penekanan pelayanan secara aktif kepada pelanggan merupakan faktor yang penting untuk perusahaan agar lebih berorientasi kepada pelanggan. Penekanan kepada pelayanan juga mengidentifikasikan perusahaan mempunyai tujuan yang jelas sehingga mereka menawarkan layanannya sebaik produk utama yang ditawarkan (Kitching et al., 2009).

Kualitas pelayanan didefinisikan sebagai pertimbangan evaluatif pelanggan tentang keseluruhan mutu yang terbaik/superioritas yang sungguh-sungguh ada didalam ketersediaan manfaat manfaat yang dikehendaki sehingga kualitas pelayanan dapat mengurangi biaya-biaya, memperluas market share, meningkatkan profitabilitas dan dapat mengurangi elastisitas harga. Kualitas pelayanan yang baik akan mampu meningkatkan kinerja bisnis.

Daya tarik didefinisikan sebagai ketertarikan pelanggan untuk memiliki suatu produk atas kinerja produk. Daya tarik produk merupakan ketertarikan dari semua komponenkomponen yang membentuk produk, sehingga produk tersebut mempunyai nilai tambah dimata pelanggannya. Kahn et al., (2002) menyatakan bahwa daya tarik produk berpengaruh positif terhadap strategi berbasis layanan. 
Metode Structural Equation Modelling (SEM) untuk mengetahui faktor apa saja yang paling berpengaruh terhadap kinerja bisnis. Kinerja bisnis dipengaruhi setidaknya oleh tiga faktor yaitu kualitas pelayanan, daya tarik produk dan strategi bersaing berorientasi pelanggan. SEM digunakan sebagai alat untuk mengetahui faktor mana yang paling signifikan mempengaruhi kinerja bisnis. Metode SEM digunakan karena metode ini dapat menganalisis beberapa variabel laten dalam penelitian yang tidak dapat diukur secara kuantitatif sehingga memerlukan analisis lebih lanjut.

\section{TINJAUAN PUSTAKA}

\subsection{Konse p-konsep Dasar}

\subsubsection{Analisis Structural Equation Modelling}

Structural Equation Modeling (SEM) adalah suatu teknik statistik yang mampu menganalisis pola hubungan antara konstruk laten dan indikatornya, konstruk laten yang satu dengan lainnya, serta kesalahan pengukuran secara langsung. SEM memungkinkan dilakukannya analisis di antara beberapa variabel dependen dan independen secara langsung (Hair et al., 2010).

Pada penelitian ini variabel laten yang digunakan ada 4, dimana setiap variabel laten mempunyai 3 indikator sehingga terdapat 12 indikator dalam penelitian ini. Untuk menguji indikator mana yang paling signifikan, alat analisis data yang dipakai adalah Structural Equation Model dari paket statistik AMOS. Sebagai sebuah model persamaan struktur, AMOS sering digunakan dalam penelitian-penelitian pemasaran dan manajemen strategic (Hair et al., 2010). Model kausal AMOS menunjukkan pengukuran dan masalah yang struktural, dan digunakan untuk menganalisa dan menguji model hipotesis.

Penelitian ini akan menggunakan dua macam teknik analisis yaitu :

a. Confirmatory Factor Analysis pada SEM yang digunakan untuk mengkonfirmasikan faktor-faktor yang paling dominan dalam satu kelompok variabel.

b. Regression Weight pada SEM yang digunakan untuk meneliti seberapa besar hubungan antar variabel.

\subsubsection{Analisis Faktor Konfirmatori (CFA)}

Analisis faktor konfirmatori digunakan untuk menegaskan bahwa semua indikator mengelompokan sendiri kedalam faktor-faktor yang berkaitan dengan bagaimana peneliti telah menghubungkan indikator-indikator dengan variabel-variabel laten. Model-model CFA dalam SEM digunakan untuk menilai peranan kesalahan pengukuran dalam model, untuk validasi model multifaktorial, dan untuk menentukan efek-efek kelompok pada faktor-faktor.

Model umum Analisis Faktor konfirmatori adalah sebagai berikut:

$$
\mathbf{x}=\Lambda_{X} \xi+\delta
$$

Dengan:

$\mathbf{x} \quad$ : merupakan vektor bagi peubah-peubah indikator berukuran $\mathrm{q}$ x 1

$\Lambda_{X} \quad$ :merupakan matriks bagi faktor loading $(\lambda)$ atau koefisien yang menunjukan hubungan $X$ dengan $\xi$ berukuran $\mathrm{q} \times \mathrm{n}$

$\xi \quad:(k s i)$, merupakan vektor bagi peubah-peubah laten berukuran $\mathrm{n} \times 1$

$\boldsymbol{\delta} \quad$ : vektor bagi galat pengukuran berukuran q x 1

Bila dinyatakan dalam bentuk matriks adalah sebagai berikut, 


$$
\left[\begin{array}{l}
x_{1} \\
x_{2} \\
\vdots \\
x_{q}
\end{array}\right]=\left[\begin{array}{cccc}
\lambda_{11} & \lambda_{12} & \cdots & \lambda_{1 n} \\
\lambda_{21} & \lambda_{22} & \cdots & \lambda_{2 n} \\
\vdots & \vdots & \ddots & \vdots \\
\lambda_{n 1} & \lambda_{n 2} & \cdots & \lambda_{n n}
\end{array}\right]\left[\begin{array}{c}
\xi_{1} \\
\xi_{2} \\
\vdots \\
\xi_{n}
\end{array}\right]+\left[\begin{array}{c}
\delta_{1} \\
\delta_{2} \\
\vdots \\
\delta_{q}
\end{array}\right]
$$

Tingkat signifikansi yang perlu dipertimbangkan dalam penelitian apabila probabilitas $<0.05$ dan Goodness of Fit nya terpenuhi.

Menurut Hair et al., (2010) terdapat tujuh langkah yang harus dilakukan apabila menggunakan Structural Equation Model yaitu :

\section{Pengembangan Model Teoritis}

Dilakukan dengan melakukan serangkaian eksploitasi ilmiah melalui telaah pustaka guna mendapatkan justifikasi atas model teoritis yang akan dikembangkan. SEM digunakan bukan untuk menghasilkan sebuah model, tetapi digunakan untuk mengkonfirmasi model teoritis tersebut melalui data empirik.

\section{Pengembangan Diagram Path}

Dalam langkah kedua ini, model teoritis yang telah dibangun pada tahap pertama akan digambarkan dalam sebuah diagram path, yang akan mempermudah untuk melihat hubungan-hubungan kausalitas yang ingin diuji. Dalam diagram path, hubungan antar konstruk akan dinyatakan melalui anak panah. Anak panah yang lurus menunjukkan sebuah hubungan kausal yang langsung antara satu konstruk dengan konstruk lainnya. Sedangkan garis-garis lengkung antara konstruk dengan anak panah pada setiap ujungnya menunjukkan korelasi antara konstruk- konstruk yang dibangun dalam path diagram yang dapat dibedakan dalam dua kelompok, yaitu :

a. Exogenous constructs yang dikenal juga sebagai source variables atau independent variables yang tidak diprediksi oleh variabel yang lain dalam model.

b. Endogenous constructs yang merupakan faktor-faktor yang diprediksi oleh satu atau beberapa konstruk. Konstruk endogen dapat memprediksi satu atau beberapa konstruk endogen lainnya, tetapi konstruk eksogen hanya dapat berhubungan kausal dengan konstruk endogen.

\section{Konversi Diagram Path ke dalam persamaan}

Persamaan yang didapat dari path diagram yang dikonversikan terdiri dari :

a. Structural equation yang dirumuskan untuk menyatakan hubungan kausalitas antara berbagai konstruk.

b. Persamaan spesifikasi model pengukuran (measurement model) dimana harus serangkaian matriks yang menunjukkan korelasi yang dihipotesisikan antar konstruk atau variabel. Komponen-komponen ukuran mengidentifikasi latent variables dan komponen-komponen struktural mengevaluasi hipotesis hubungan kausal, antara latent variables pada model kausal dan menunjukkan sebuah pengujian seluruh hipotesis dari model sebagai satu keseluruhan (Hair et al., 2010).

Model persamaan struktural dapat dinyatakan sebagai berikut :

$\boldsymbol{\eta}=\boldsymbol{\beta} \boldsymbol{\eta}+\boldsymbol{\Gamma} \xi+\boldsymbol{\zeta}$

Model pengukuran dinyatakan sebagai berikut :

$\boldsymbol{y}_{\boldsymbol{i}}=\wedge \boldsymbol{y}_{\boldsymbol{i}} \boldsymbol{\eta}+\boldsymbol{\varepsilon}_{\boldsymbol{i}}$

$x_{i}=\Lambda_{x i} \xi+\delta_{i}$

Keterangan :

$\boldsymbol{\eta}$ : vektor variael faktor endogenus berukuran $\mathrm{m} \times 1$

$\xi \quad$ : vektor variabel faktor eksogenus berukuran $\mathrm{n} \times 1$

$\boldsymbol{\beta}$ : matriks koefisien regresi antar $\eta$ berukuran $\mathrm{m} \times \mathrm{m}$

$\Gamma \quad$ : matriks koefisien regresi $\xi$ terhadap $\eta$ berukuran $\mathrm{m} \times \mathrm{n}$ 
$\zeta \quad$ : vektor galat pada persamaan structural berukuran $\mathrm{m} \times 1$

$\boldsymbol{y} \quad$ : vektor variabel indikator untuk variabel endogenus berukuran $\mathrm{p} \times 1$

$\Lambda_{y i} \quad:$ matriks koefisien regresi $y_{i}$ terhadap $\eta$ berukuran $\mathrm{p} \times \mathrm{m}$

$\boldsymbol{\varepsilon}_{\boldsymbol{i}} \quad$ : vektor galat pengukuran $y_{i}$ berukuran $\mathrm{p} \mathrm{x} 1$

$\boldsymbol{x} \quad$ : vektor variabel indikator untuk variabel eksogenus berukuran q x 1

$\Lambda_{x i} \quad:$ matriks koefisien regresi $x_{i}$ terhadap $\xi$ berukuran q x $\mathrm{n}$

$\boldsymbol{\delta}_{\boldsymbol{i}} \quad$ : vektor galat pengukuran $x_{i}$

\section{Memilih matriks input dan estimasi model}

SEM menggunakan input data yang hanya menggunakan matriks varians/kovarians atau matrik korelasi untuk keseluruhan estimasi yang dilakukan. Matriks kovarian digunakan karena SEM memiliki keunggulan dalam menyajikan perbandingan yang valid antara populasi yang berbeda atau sampel yang berbeda, yang tidak dapat disajikan oleh korelasi. Hair et al, (2010) menganjurkan agar menggunakan matriks varians/ kovarians pada saat pengujian teori sebab lebih memenuhi asumsiasumsi metodologi dimana standard error yang dilaporkan akan menunjukkan angka yang lebih akurat dibanding menggunakan matriks korelasi.

Beberapa teknik estimasi yang tersedia dalam SEM adalah : Maximum Likelihood Estimation (ML), Generalized Least Square Estimation (GLS), Unweighted Least Square Estimation, Scale Free Least Square Estimation, Asymptotically DistributionFree Estimation (ADF).

\section{Kemungkinan munculnya masalah identifikasi}

Problem identifikasi pada prinsipnya adalah problem mengenai ketidakmampuan dari model yang dikembangkan untuk menghasilkan estimasi yang unik (berpengaruh secara langsung/tidak langsung). Bila setiap kali estimasi dilakukan muncul masalah identifikasi yaitu ada variabel yang tidak berpengaruh, maka sebaiknya model dipertimbangkan ulang dengan mengembangkan lebih banyak konstruk.

\section{Evaluasi krite ria goodness of fit}

Pada langkah ini dilakukan pengujian terhadap kesesuaian model melalui telaah terhadap berbagai kriteria goodness of fit. Berikut ini disajikan beberapa indeks kesesuaian dan cut off value untuk menguji apakah sebuah model dapat diterima atau ditolak.

\subsubsection{Uji Kesesuaian dan Uji Statistik}

Untuk melakukan uji kesesuaian dan statistik diperlukan beberapa indeks kesesuaian dan cut-off-volumenya untuk digunakan dalam pengujian sebuah model. Pada langkah ini kesesuaian model dievaluasi, melalui telaah terhadap berbagai kriteria Goodness of Fit. Tindakan pertama yang dilakukan adalah mengevaluasi data yang digunakan memenuhi asumsi-asumsi SEM, yakni ukuran sampel, normalitas, linearitas, outlier, multikolenearitas, dan singularitas. Dalam analisis SEM tidak ada alat uji statistik tunggal untuk mengukur atau menguji hipotesis mengenai model (Ferdinand, 2002).

Tabel 1. Kriteria Goodness of Fit Indeks

\begin{tabular}{ccc}
\hline Goodness of Fit Index & \multicolumn{1}{c}{ Keterangan } & Cut of Point \\
\hline$x^{2}-$ Chi-square & $\begin{array}{l}\text { Menguji kesamaan kovarians populasi yang diestimasi } \\
\text { dengan kovarians sampel } \\
\text { (kesesuaian modeldengan data) }\end{array}$ & $\begin{array}{c}\text { Diharapkan } \\
\text { kecil }\end{array}$ \\
Probability & Uji signifikansiterhadap perbedaan matrik kovarians & $\geq 0,05$ \\
\hline
\end{tabular}




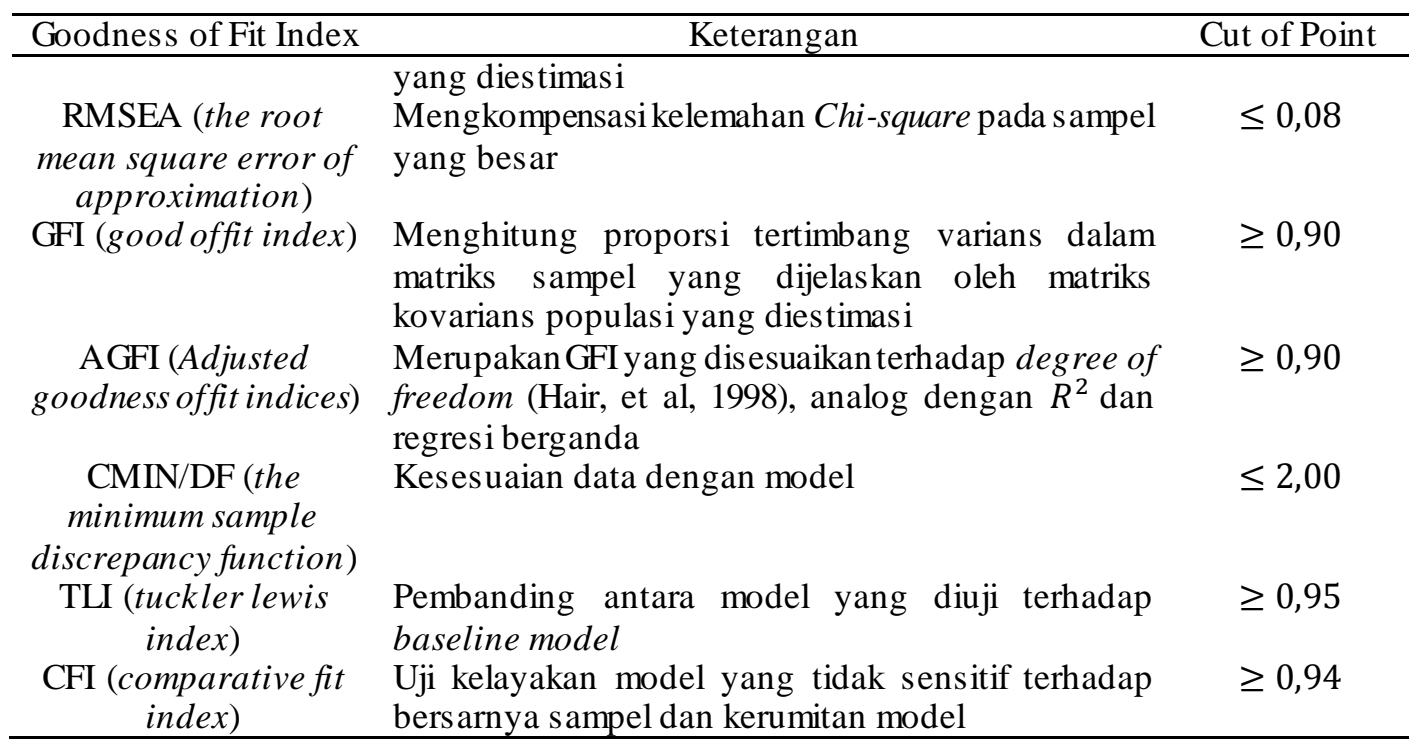

\subsubsection{Variabel Independen dan Dependen Berdistribusi Normal Multivariat}

Normal multivariat adalah perluasan dari univariat normal. Asumsi yang harus dipenuhi antara lain data pada variabel bebas seharusnya berdistribusi normal multivariat dan adanya kesamaan matriks varians kovarians antar kelompok/populasi. Oleh karena itu perlu adanya uji normalitas multivariate yang bertujuan untuk mengetahui apakah data mengikuti distribusi normal multivariat. Pengujian normal multivariat adalah dengan mengamati nilai skewness pada data yang digunakan, apabila nilai CR pada skewness data berada pada rentang antara \pm 2.58 pada taraf signifikansi 0.01 maka data berdistribusi normal multivariat.

\subsubsection{Jarak Mahalonobis}

Identifikasi outlier pada multivariat umumnya didasarkan pada jarak Mahalanobis Johnson dan Wichern (1998) menyatakan bahwa pengamatan ke- $i$ didefinisikan sebagai outlier jika jaraknya lebih besar dari nilai chi-square pada sejumlah variabel. Perhitungan tersebut sebagai berikut:

$M D^{2}=\left(x_{i}-\mu\right)^{t} \sum\left(x_{i}-\mu\right), i=1,2, \ldots, n$

dengan:

$$
\begin{array}{ll}
\mu & \text { : vektor rata-rata } \\
\sum_{\mathrm{n}} & \text { : matriks kovarian } \\
& \text { : banyaknya pengamatan }
\end{array}
$$

Sebuah pengamatan $x_{i}$ diidentifikasikan sebagai outlier jika jarak mahalanobisnya lebih besar dari nilai chi-square tabel dengan taraf signifikansi $(\alpha)$ dan derajat bebas $p\left(M D^{2}>x_{p(\alpha)}^{2}\right)$ atau setara dengan $M D_{i}>\sqrt{x_{p(\alpha)}^{2}}$.

\subsubsection{Multicollinearity dan Singularity}

Multikolinearitas dapat dideteksi dari determinan matriks kovarians. Nilai determinan matriks kovarians yang sangat kecil (extremely small) memberi indikasi adanya problem multikolenearitas atau singularitas. Pada umumnya program-program komputer SEM telah menyediakan fasilitas "warning" setiap kali terdapat indikasi multikolenearitas atau singularitas.

Perlakuan data (data treatment) yang dapat dilakukan adalah dengan mengeluarkan variabel yang menyebabkan singularitas tersebut. Bila singularitas dan multikolenearitas 
ditemukan dalam data yang dikeluarkan tersebut, salah satu treatmenr yang dapat digunakan adalah dengan menciptakan "composite variables", dan gunakan composite variables tersebut dalam analisis selanjutnya.

Setelah seluruh asumsi SEM dipenuhi, dilakukan penentuan kriteria yang akan digunakan untuk mengevaluasi model dan pengaruh-pengaruh yang ditampilkan dalam model.

\subsubsection{Interpretasi dan Modifikasi Model}

Langkah terakhir adalah menginterpretasikan model dan memodifikasi model bagi model-model yang tidak memenuhi syarat pengujian yang dilakukan. Hair et al., (2010) memberikan pedoman untuk mempertimbangkan perlu tidaknya memodifikasi sebuah model dengan melihat jumlah residual yang dihasilkan oleh model.

\subsubsection{Kinerja Bisnis}

Kinerja bisnis merupakan faktor yang umum digunakan untuk mengukur dampak dari strategi pelayanan yang diterapkan organisasi. Dengan kata lain, kinerja bisnis adalah konsep untuk menilai prestasi atas layanan aktivitas bisnis yang dilakukan oleh organisasi. Indikator kinerja bisnis yang digunakan dalam penelitian ini menurut Spencer et al., (2009) adalah sebagai berikut: (1) pertumbuhan pelanggan, (2) pertumbuhan profitabilitas, dan (3) pertumbuhan penjualan.

\subsubsection{Strategi bersaing berorientasi pelanggan}

Strategi bersaing berorientasi pelanggan yaitu serangkain komitmen dan tindakan yang terintegrasi dan terkoordinasi yang dirancang untuk menyediakan nilai bagi pelanggan dan mendapatkan keunggulan kompetitif dengan mengeksploitasi kompetensi inti dari pasar produk tunggal/individual dan spesifik yang berorientasi pada pelayanan terhadap pelanggan. Indikator strategi bersaing berorientasi pelanggan yang digunakan dalam penelitian ini menurut Kitching et al., (2009) adalah sebagai berikut:

(1) keunggulan pada harga, (2) keunggulan pada layanan pelanggan, dan (3) keunggulan pada tingkat keunikan desain kafe.

\subsubsection{Kualitas pelayanan}

Kualitas Pelayanan dapat didefinisikan sebagai penyampaian secara excellent/superior dibandingkan dengan harapan pelanggan mengenai (1) teknik organisasi dan fungsi kualitas, (2) jasa pelayanan produk, jasa pelayanan pengiriman dan jasa pelayanan lingkukangan atau (3) reliability, responsiviness, emphaty, assurance dan tangible. Indikator kualitas pelayanan menurut Hadiyati, (2014) adalah sebagai berikut:

(1) memberikan layanan kemudahan dalam membayar, (2) mengutamakan penyajian pesanan dengan cepat, dan (3) fokus pada kesesuaian order menu.

\subsubsection{Daya Tarik Produk}

Daya tarik merupakan ketertarikan dari semua komponen-komponen yang membentuk produk, sehingga produk tersebut mempunyai nilai tambah dimata pelanggannya. Indikator daya tarik produk yang digunakan dalam penelitian ini menurut Khan et al., (2002) adalah sebagai berikut: (1) menarik pelanggan untuk mencoba produk yang ditawarkan, (2) menjaga pelanggan untuk tidak beralih di masa depan, dan (3) membuat nilai tambah produk dimata pelanggan. 


\subsection{Pengaruh antar Variabel}

\subsubsection{Pengaruh Kualitas pelayanan terhadap Strategi bersaing berorientasi pelanggan}

Menurut Stewart, (2016), kualitas pelayanan yang dirasakan oleh pelanggan memberikan persepsi untuk menggunakan produk karena memberikan manfaat yang kuat. Strategi bersaing yang dilakukan perusahaan perlu berorientasi pada pelayanan kepada seorang pelanggan atau sekelompok pelanggan agar merasa produk yang digunakan sesuai dengan manfaat yang harapkan. Semakin tinggi tingkat kualitas pelayanan, semakin tinggi strategi bersaing berorientasi pelanggan yang digunakan. Berdasarkan uraian tersebut dapat dirumuskan menjadi hipotesis pertama sebagai berikut:

Hipotesis 1 :

$\mathrm{H}_{0}: \beta_{i}=0$, tidak ada hubungan antara kualitas pelayanan dengan strategi bisnis berbasis

layanan

$\mathrm{H}_{1}: \beta_{i} \neq 0$, ada hubungan antara kualitas pelayanan dengan strategi bisnis berbasis layanan

\subsubsection{Pengaruh Kualitas pelayanan terhadap Kine rja Bis nis}

Kualitas layanan yang baik mampu memberikan rasa nyaman bagi pelanggan untuk menjadi bagian dari bisnis, hal ini mampu meningkatkan kinerjanya. Hadiyati, (2014) menyatakan bahwa kualitas pelayanan yang baik akan mampu meningkatkan kinerja bisnis. Berdasarkan uraian tersebut dapat dirumuskan menjadi hipotesis kedua sebagai berikut:

Hipotesis 2:

$\mathrm{H}_{0}: \beta_{i}=0$, tidak ada hubungan antara kualitas pelayanan dengan kinerja bisnis

$\mathrm{H}_{1}: \beta_{i} \neq 0$, ada hubungan antara kualitas pelayanan dengan kinerja bisnis

\subsubsection{Pengaruh Daya Tarik Produk terhadap Strategi bersaing berorientasi pelanggan \\ Khan dan Strong, (2016) mengemukakan bahwa daya tarik didefinisikan sebagai} ketertarikan untuk membeli dari pelanggan atas produk. Daya tarik produk diungkapkan dari perspektif pemasar selalu dikaitkan dengan spesifikasi, fitur, fungsi atau kinerja dari suatu produk. Daya tarik produk berpengaruh positif terhadap strategi bersaing berorientasi pelanggan. Berdasarkan uraian tersebut dapat dirumuskan menjadi hipotesis ketiga sebagai berikut:

Hipotesis 3:

$\mathrm{H}_{0}: \beta_{i}=0$, tidak ada hubungan antara daya tarik produk dengan strategi bisnis berbasis layanan

$\mathrm{H}_{1}: \beta_{i} \neq 0$, ada hubungan antara daya tarik produk dengan strategi bisnis berbasis layanan

\subsubsection{Pengaruh Daya Tarik Produk terhadap Kinerja bis nis}

Kahn et al., (2002) berpendapat bahwa daya tarik suatu produk terlepas dilihat dari bentuk barang atau jasa adalah merupakan peluang nilai bagi perusahaan agar dapat dipergunakan untuk meraih margin keuntungan yang lebih besar lagi. Arti lain dari kualitas adalah berkurangnya persoalan bagi perusahaan terkait dengan komplain dan pengembalian produk oleh pelanggan. Daya tarik produk berpengaruh positif terhadap strategi bersaing berorientasi pelanggan. Produk yang mempunyai daya tarik tinggi 
mempengaruhi strategi bersaing berorientasi pelanggan (Kahn et al., 2002). Berdasarkan uraian tersebut dapat dirumuskan menjadi hipotesis keempat sebagai berikut:

Hipotesis 4:

$\mathrm{H}_{0}: \beta_{i}=0$, tidak ada hubungan antara daya tarik produk dengan kinerja bisnis

$\mathrm{H}_{1}: \beta_{i} \neq 0$, ada hubungan antara daya tarik produk dengan kinerja bisnis

\subsubsection{Pengaruh Strategi bersaing berorientasi pelanggan terhadap Kinerja bisnis}

Pelaku jasa dapat menawarkan beberapa pelayanan kepada sejumlah besar pelanggannya, pelayanan ini juga harus memberikan penekanan kepada perusahaan untuk berorientasi pada layanan menjadi lebih besar (Kitching et al., 2009). Penekanan kepada pelayanan juga mengidentifikasikan perusahaan mempunyai tujuan yang jelas sehingga mereka menawarkan layanannya sebaik produk utama yang ditawarkan (Spencer et al., 2009). Berdasarkan uraian tersebut dapat dirumuskan menjadi hipotesis kelima sebagai berikut:

Hipotesis 5:

$\mathrm{H}_{0}: \beta_{i}=0$, tidak ada hubungan antara strategi bisnis berbasis layanan dengan kinerja bisnis $\mathrm{H}_{1}: \beta_{i} \neq 0$, ada hubungan antara strategi bisnis berbasis layanan dengan kinerja bisnis

\section{METODE PENELITIAN}

\subsection{Jenis dan Sumber Data}

Data yang akan digunakan dalam penelitian ini adalah data primer yang dikumpulkan oleh peneliti melalui wawancara dengan menggunakan daftar pertanyaan kepada para pemilik kafe yaitu coffe shop di Kecamatan Tembalang dan Kecamatan Banyumanik melalui kuesioner.

\subsection{Populasi dan Sampel}

Populasi dalam penelitian ini adalah pemilik kafe yaitu coffe shop di Kecamatan Tembalang dan Kecamatan Banyumanik sejumlah 116 responden. Penelitian ini menggunakan sensus, dimana seluruh populasi yang bersedia dijadikan responden.

\subsection{Metode Pengumpulan Data}

Data dikumpulkan menggunakan metode wawancara berdasarkan daftar pertanyaan kepada para pemilik kafe . Pernyataan-pernyataan dalam daftar pertanyaan tertutup dibuat dengan memberikan nilai antara 1-10 untuk mendapatkan data yang bersifat kontinu, dimana nilai yang didapatkan dapat berupa bilangan pecahan dan bulat.

\subsection{Tahapan Analis is Data}

Dalam penelitian ini variabel endogen yang digunakan adalah Kinerja Bisnis (KB) dan Strategi Bisnis Berbasis Layanan (SBBL) serta dengan variabel eksogen yaitu Kualitas Pelayanan (KP) dan Daya Tarik Produk (DTP). Dengan masing-masing indikator Kinerja Bisnis (KP) yaitu memberikan layanan kemudahan dalam pembayaran $\left(X_{1}\right)$, mengutamakan penyajian pesanan dengan cepat $\left(X_{2}\right)$, dan fokus pada kesesuaian order menú $\left(X_{3}\right)$. Indikator Daya Tarik Produk (DTP) yaitu menarik pelanggan untuk mencoba produk yang ditawarkan $\left(X_{4}\right)$, menjaga pelanggan untuk tidak beralih ke kafe lain $\left(X_{5}\right)$, membuat nilai tambah produk dimata pelanggan $\left(X_{6}\right)$. Indikator Strategi Bisnis Berbasis Layanan (SBBL) yaitu keunggulan pada harga $\left(Y_{1}\right)$, keunggulan pada layanan pelanggan $\left(Y_{2}\right)$, keunggulan pada tingkat keunikan desain kafe $\left(Y_{3}\right)$. Dan indikator Kinerja Bisnis (KB) yaitu pertumbuhan pelanggan $\left(Y_{4}\right)$, pertumbuhan profitabilitas $\left(Y_{5}\right)$, pertumbuhan 
penjualan $\left(Y_{6}\right)$. Software yang digunakan dalam penelitian berikut adalah AMOS versi 24 . Tahapan dalam analisis data yang diperlukan adalah sebagai berikut:

1. Melakukan serangkaian eksploitasi ilmiah atau telaah pustaka untuk mendapatkan faktor apa saja yang mempengaruhi kinerja bisnis dan indikator apa saja yang mempengaruhi setiap faktor.

2. Menyusun kuesioner penelitian berdasarkan telaah pustaka yang dilakukan.

3. Mengumpulkan data primer melalui wawancara kepada pemilik kafe di Kecamatan Tembalang dan Kecamatan Banyumanik.

4. Melakukan uji validitas dan reliabilitas terhadap data yang diperoleh yaitu dengan menggunakan 30 sampel. Apabila uji validitas dan reliabilitas tidak terpenuhi maka indikator yang tidak valid dihapus dari kuesioner dan dilakukan wawancara kembali untuk memperoleh data primer serta dilakukan uji validitas dan reliabilitas kembali.

5. Melakukan analisis SEM dengan menggunakan software AMOS versi 24 sehingga diperoleh model awal.

6. Melakukan analisis CFA dan GOF untuk faktor endogen dan faktor eksogen pada model. Apabila ada indikator yang tidak signifikan maka akan dihapus dari model.

7. Melakukan uji asumsi dan GOF pada model yang memenuhi analisis CFA untuk faktor endogen dan eksogen. Apabila model tidak sesuai maka dilakukan pendekatan non parametrik (PLS).

8. Mendapatkan model akhir dari penelitian.

9. Melakukan interpretasi dari model yang didapatkan.

\section{HASIL DAN PEMBAHASAN}

\subsection{Analisis Faktor Konfirmatori}

Analisis konfirmatori bertujuan untuk menguji validitas dari indikator-indikator yang membangun masing-masing variabel laten atau konstruk dalam model penelitian. Analisis faktor konfirmatori dibagi menjadi dua, yakni analisis faktor konfirmatori eksogen dan analisis faktor konfirmatori endogen.

\subsubsection{Analisis Faktor Konfirmatori Eksogen}

Analisis faktor konfirmatori eksogen dalam penelitian ini, menguji validitas dari indikator pembentuk variabel laten kualitas pelayanan dan daya tarik produk. Dengan menggunakan software AMOS versi 24 diperoleh :

Tabel 2. Hasil Analisis Faktor Konfirmatori Eksogen Full

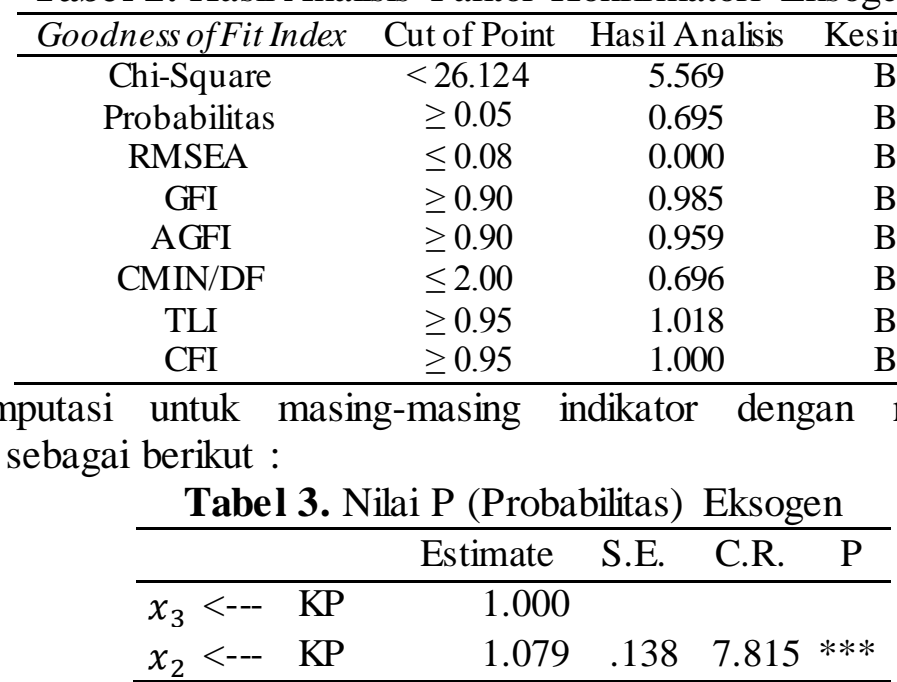




\begin{tabular}{llrlll}
\hline & & Estimate & S.E. & C.R. & P \\
\hline$x_{1}<---$ & KP & .972 & .125 & 7.742 & $* * *$ \\
$x_{6}<---$ & DTP & 1.000 & & & \\
$x_{5}<---$ & DTP & 1.306 & .200 & 6.518 & $* * *$ \\
$x_{4}<---$ & DTP & 1.307 & .202 & 6.458 & $* * *$ \\
\hline
\end{tabular}

Berdasarkan Tabel 2, dapat disumpulkan bahwa faktor eksogen dapat digunakan atau model fit. Berdasarkan Tabel 3, dengan masing-masing indikator memiliki nilai $\mathrm{P}<0.05$ yaitu dengan $\mathrm{P}$ mendekati 0 atau sangat signifikan, maka dapat disimpulkan bahwa seluruh indikator telah dapat menjelaskan masing-masing variabel faktor.

\subsubsection{Analisis Faktor Konfirmatori Endogen}

Analisis faktor konfirmatori endogen dalam penelitian ini, menguji validitas dari indikator pembentuk variabel laten strategi bisnis berbasis layanan dan kinerja bisnis. Dengan menggunakan software AMOS versi 24 diperoleh :

Tabel 4. Hasil Analisis Faktor Konfirmatori Endogen

\begin{tabular}{lcll}
\hline Goodness of Fit Index & Cut of Point & Hasil Analisis & Kesimpulan \\
\hline Chi-Square & $<26.124$ & 16.180 & Baik \\
Probabilitas & $\geq 0.05$ & 0.040 & Marginal \\
RMSEA & $\leq 0.08$ & 0.094 & Marginal \\
GFI & $\geq 0.90$ & 0.957 & Baik \\
AGFI & $\geq 0.90$ & 0.887 & Baik \\
CMIN/DF & $\leq 2.00$ & 2.022 & Marginal \\
TLI & $\geq 0.95$ & 0.955 & Baik \\
CFI & $\geq 0.95$ & 0.976 & Baik
\end{tabular}

Hasil komputasi untuk masing-masing indikator dengan nilai $\mathrm{P}$ (Probabilitas) diperoleh hasil sebagai berikut :

Tabel 5. Nilai P (Probabilitas) Endogen

\begin{tabular}{|c|c|c|c|c|c|}
\hline & & Estimate & S.E. & C.R. & $\mathrm{P}$ \\
\hline$y_{3}<---$ & SBBL & 1.000 & & & \\
\hline$y_{2}<---$ & SBBL & 0.995 & .134 & 7.455 & $* * *$ \\
\hline$y_{1}<---$ & SBBL & 0.976 & .131 & 7.438 & $* * *$ \\
\hline$y_{4}<---$ & $\mathrm{KB}$ & 1.000 & & & \\
\hline$y_{5}<---$ & $\mathrm{KB}$ & 1.042 & .097 & 10.773 & $* * *$ \\
\hline$y_{6}<---$ & $\mathrm{KB}$ & 1.114 & .107 & 10.391 & $* * *$ \\
\hline
\end{tabular}

Berdasarkan Tabel 4, dapat disumpulkan bahwa faktor endogen dapat digunakan atau model fit. Berdasarkan Tabel 5, dengan masing-masing indikator memiliki nilai $\mathrm{P}<0.05$ yaitu dengan $\mathrm{P}$ mendekati 0 atau sangat signifikan, maka dapat disimpulkan bahwa seluruh indikator telah dapat menjelaskan masing-masing variabel faktor.

\subsection{Structural Equational Modelling (SEM)}

\subsubsection{Evaluasi Asumsi SEM}

\subsubsection{Normalitas Multivariat}

Dari hasil pengolahan data pada software AMOS versi 24 didapatkan nilai C.R. Mutivariate $=0.816$ yaitu berada diluar rentang \pm 2.58 . Dengan demikian maka dapat disimpulkan bahwa data berdistribusi normal multivariat. 


\subsubsection{Bebas Outlier}

Dari hasil pengolahan data pada software AMOS versi 24 didapatkan jarak mahalonis terbesar yaitu 25,141. Dan pada penelitian ini berdasarkan nilai Chi-square pada derajat bebas 12 (jumlah indikator) pada tingkat $\mathrm{p}<0.01$ adalah 26,217. Maka dapat disimpulkan bahwa data yang memiliki jarak mahalanobis lebih dari nilai $\chi^{2}=26,217$ adalah data yang terindikasi multivariat outlier, maka pada penelitian ini terlihat bahwa seluruh obeservasi tidak terindikasi adanya outlier.

\subsubsection{Multikolinie ritas}

Berdasarkan nilai determinan dari matriks kovarian pada software AMOS versi 24 yaitu sebesar 7.418, yang artinya sangat jauh dari nol sehingga dapat dikatakan bahwa tidak terdapat multikolinieritas pada data.

\subsubsection{Pengujian Kriteria Goodness of Fit}

Pengujian Goodness of Fit dengan menggunakan software AMOS versi 24 diperoleh :

Tabel 6. Hasil Goodness of Fit Full Model

\begin{tabular}{cccc}
\hline Goodness of Fit Index & Cut of Point & Hasil Analisis & Kesimpulan \\
\hline Chi-Square & $<73.683$ & 61.763 & Baik \\
Probabilitas & $\geq 0.05$ & 0.088 & Baik \\
RMSEA & $\leq 0.08$ & 0.050 & Baik \\
GFI & $\geq 0.90$ & 0.927 & Baik \\
AGFI & $\geq 0.90$ & 0.881 & Marginal \\
CMIN/DF & $\leq 2.00$ & 1.287 & Baik \\
TLI & $\geq 0.95$ & 0.971 & Baik \\
CFI & $\geq 0.95$ & 0.979 & Baik \\
\hline
\end{tabular}

Dari hasil analisis terhadap kriteria Goodness of Fit, dapat diketahui bahwa variabel faktor dan indikator yang digunakan untuk membentuk sebuah model penelitian, telah layak digunakan. Semua kriteria yang digunakan, memiliki nilai yang baik, sehingga model dalam penelitian ini dapat diterima dengan baik.

\subsubsection{Interpretasi Model}

Berdasarkan hasil software AMOS versi 24, diperoleh hasil komputasi hubungan antara variabel faktor yang satu dengan variabel faktor lainnya yaitu sebagai berikut :

1. Variabel indikator yang paling mempengaruhi kualitas pelayanan adalah variabel penyajian pesanan yang cepat (0.809). Variabel kemudahan dalam pembayaran (0.797), fokus pada kesesuaian menu (0.750).

2. Variabel yang paling mempengaruhi daya tarik produk adalah variabel menjaga pelanggan untuk tidak beralih dimasa depan (0.851). Variabel menarik pelanggan untuk mencoba produk yang ditawarkan (0.798), membuat nilai tambah produk dimata pelanggan (0.627).

3. Variabel yang paling mempengaruhi strategi bisnis berbasis layanan adalah variable keunggulan pada tingkat desain kafe (0.785). Variabel keunggulan pada harga (0.770) dan variabel keunggulan pada layanan pelanggan (0.762).

4. Variabel yang paling mempengaruhi loyalitas produk adalah variabel pertumbuhan profit (0.881). Variabel pertumbuhan penjualan (0.851), pertumbuhan pelanggan (0.826). 


\subsubsection{Pengujian Hipotes is}

Berdasarkan hasil software AMOS versi 24, dari beberapa hipotesis yang diajukan dapat disimpulkan sebagai berikut :

1. Ada hubungan antara ada hubungan antara kualitas pelayanan dengan strategi bisnis berbasis layanan

2. Ada hubungan antara kualitas pelayanan dengan kinerja bisnis

3. Tidak ada hubungan antara daya tarik produk dengan strategi bisnis berbasis layanan

4. Ada hubungan antara daya tarik produk dengan kinerja bisnis

5. Ada hubungan antara strategi bisnis berbasis layanan dengan kinerja bisnis

\section{PENUTUP}

\subsection{Kesimpulan}

Berdasarkan hasil analisis dan pembahasan yang telah dipaparkan pada bab sebelumnya, maka dapat diambil kesimpulan sebagai berikut:

1. Berdasarkan hasil pengujian hipotesis, hanya daya tarik produk yang tidak mempengaruhi strategi bisnis berbasis layanan, sedangkan kualitas pelayanan mempengaruhi strategi bisnis berbasis layanan. Strategi bisnis berbasis layanan juga memberikan pengaruh yang positif terhadap kinerja bisnis.

2. Faktor kualitas pelayanan adalah variabel yang paling mempengaruhi strategi bisnis berbasis layanan sebesar 0.349 atau $34.9 \%$ dan faktor kualitas pelayanan juga paling besar mempengaruhi kinerja bisnis sebesar 0.361 atau 36.1\%. Faktor daya tarik produk adalah variabel yang paling lemah mempengaruhi strategi bisnis berbasis layanan yaitu sebesar 0.219 atau $21.9 \%$ dan faktor strategi bisnis berbasis layanan berpengaruh paling lemah terhadap kinerja bisnis yaitu sebesar 0.239 atau $23.9 \%$.

3. Indikator yang paling mempengaruhi strategi bisnis berbasis layanan adalah keunggulan pada tingkat desain kafe sebesar 0.785 atau $78.5 \%$. Indikator yang paling berpengaruh terhadap kinerja bisnis adalah pertumbuhan profit sebesar 0.881 atau $88.1 \%$.

4. Secara umum, kualitas pelayanan memberikan pengaruh positif terhadap strategi bisnis berbasis layanan dan kinerja bisnis. Faktor kualitas pelayanan memberikan pengaruh sebesar 0.361 atau $36.1 \%$ terhadap kinerja bisnis. Model yang disajikan telah teruji dengan baik dan dapat digunakan.

\subsection{Saran}

Pemilik kafe harus selalu memperhatikan kualitas pelayanan kafe terhadap pelanggan, karena kualitas pelayanan merupakan pertimbangan utama pelanggan untuk berkunjung di kafe. Berdasarkan hasil analisis penelitian kualitas pelayanan terhadap strategi bisnis berbasis layanan dan kinerja bisnis ini, untuk selanjutnya dapat dikembangkan lagi lebih banyak indikator dan faktor dari kualitas pelayanan untuk lebih meningkatkan kinerja bisnis kafe.

\section{DAFTAR PUSTAKA}

Ferdinand. 2002. Metode Penelitian Manajemen : Pedoman penelitian untuk Skripsi, Tesis, dan Desertasi Ilmu Manajemen. Semarang : Badan Penerbit Universitas Diponegoro. 
Hadiyati, E. 2014. Service Quality and Performance of Public Sector: Study on Immigration Office in Indonesia. International Journal of Marketing Studies Vol 6, No 6.

Hair, J. F., Black. W. C., Babin. B. J.; and Anderson. R. E. 2010. Multivariate Data Analysis, 7th ed. Pearson Prentice Hall, New Jersey.

Johnson, R.A. and Wichern D.W. 1998. Applied Multivariate Statistical Analysis Second Edition. Prentice-Hall International : New Jersey.

Kahn, B.K., Strong, D.M. and Wang, R.Y. 2002. Information Quality Benchmarks: Product and Service Performance. Communication of The ACM Vol. 45, No. 4ve.

Kahn, B.K., Strong, D.M. 2016. Product and Service Performance Model for Information Quality: An Update. PSP/IQ Refinement Survey.

Kaplan, R.S. and Norton, D.P. 1996. The Balanced Scorecard : Translating Strategy Into Action. Massachusetts, Harvad Business Review.

Kitching, J., Blacburn, R., Smallbone, D., and Dixon S. 2009. Bussiness Strategies and Performance During Difficult Economic Conditions. Small Bussiness Research Centre.

Spencer. X, Sarah Y., Joiner, Therese A. and Salmon S. 2009. Differentiation Strategy, Performance Measurement System and Organizational Performance: Evidence From Australia. International Journal of Bussiness.

Stewart, D. M. 2016. Designing Robust Service Encounters. International Journal of Bussiness. 